\title{
A SEMÂNTICA DAS PERGUNTAS EM PORTUGUÊS BRASILEIRO: UMA PROPOSTA SISTÊMICO-FUNCIONAL
}

\author{
Theodoro Casalotti FARHAT ${ }^{1}$ \\ Paulo Roberto GONÇALVES-SEGUNDO²
}

\section{http://dx.doi.org/10.21165/gel.v18i2.3117}

Resumo: Neste artigo, a partir dos estudos sistêmico-funcionais de Hasan (1989, 2013, entre outros), propomos uma descrição do sistema semântico de DEMANDA DE INFORMAÇÃO - também conhecido como "perguntas" - em português brasileiro. Apontamos, antes, quais são as principais frentes de pesquisa sistêmico-funcionais, assim como discutimos as noções fundamentais de realização, instanciação e rede sistêmica. Depois, explicitamos as categorias propostas em uma perspectiva tipológica e, em seguida, fazemos considerações sobre uma possível interpretação topológica do sistema. Finalmente, discutimos a possível integração do sistema proposto a outras perspectivas sistêmico-funcionais sobre o estrato da semântica, além de sugestões de próximos passos para pesquisas sobre a semântica das perguntas em português brasileiro.

Palavras-chave: Semântica. Pergunta. Demanda de informação. Semântica da mensagem. Linguística Sistêmico-Funcional.

\footnotetext{
1 Universidade de São Paulo (USP), São Paulo, São Paulo, Brasil; theo.cfar@gmail.com; https://orcid.org/0000-0002-9646-6301

2 Universidade de São Paulo (USP), São Paulo, São Paulo, Brasil; paulosegundo@usp.br; https://orcid.org/0000-0002-5592-8098
} 
- | A semântica das perguntas em português brasileiro: uma proposta sistêmico-funcional

\title{
THE SEMANTICS OF QUESTIONS IN BRAZILIAN PORTUGUESE: A SYSTEMIC-FUNCTIONAL PROPOSAL
}

\begin{abstract}
In this article, which is based on Hasan's systemic functional work (1989, 2013, among others), we provide a description of the system of DEMAND OF INFORMATION - also known as 'questions' - in Brazilian Portuguese. To do so, we first outline the main systemic functional research fronts, as well as the fundamental notions of realization, instantiation, and system network. We then explain the proposed categories in a typological perspective, with some considerations about a possible topological interpretation of the system. Finally, we discuss the possible integration of the proposed system network with other systemic functional perspectives on the stratum of semantics, as well as suggestions for the next steps for research on the semantics of questions in the lusophone context.
\end{abstract}

Keywords: Semantics. Question. Demand of information. Message semantics. Systemic Functional Linguistics.

\section{Introdução}

Neste artigo, com base no modelo de semântica da mensagem proposto por Hasan (1989, 1996, 2013; HASAN et al., 2005; FUNG; LOW, 2019), apresentamos uma proposta inicial para a descrição do sistema semântico de DEMANDA DE INFORMAÇÃO - ou, em outras palavras, de perguntas - do português brasileiro (PB). Fazemos, inicialmente, um "esboço epistemológico" da teoria de que partimos - a Linguística Sistêmico-Funcional; depois, apresentamos alguns aspectos fundamentais do estrato da semântica, com foco especial na interpretação de Hasan $(2009,2013)$ da rede interpessoal de FUNÇõES DISCURSIVAS; então, explicitamos o subsistema semântico de DEMANDA DE INFORMAÇÃO em PB, assim como suas realizações lexicogramaticais congruentes e uma possível interpretação topológica das categorias propostas; por fim, discutimos possíveis caminhos a serem percorridos a partir deste estudo, incluindo a relação da semântica da mensagem hasaniana com a semântica discursiva (MARTIN, 1992; MARTIN; ROSE, 2007) e próximos passos dos estudos de semântica da pergunta no português brasileiro.

\section{Esboço epistemológico da Linguística Sistêmico-Funcional: frentes de pesquisa e conceitos fundamentais}

A Linguística Sistêmico-Funcional (LSF), nos últimos quarenta anos, tem se estabelecido como uma referência para os estudos funcionais da linguagem em ao menos três grandes frentes: 
1) Estudos de descrição linguística primária, voltando-se à compreensão da língua como um potencial de significação que se instancia em textos. Nessa linha, destacam-se as obras fundamentais de Halliday (1985) e Matthiessen (1995) no âmbito da descrição lexicogramatical; de Martin (1992) e Hasan (2009) em termos de descrição semântica; e de Halliday e Greaves (2008) no tocante à descrição fonológica (entoação). No Brasil, destacamos os estudos lexicogramaticais de Figueredo (2011), Figueredo, Pagano e Ferreguetti (2014), Gonzaga (2011) e a obra introdutória de Fuzer e Cabral (2014).

2) Estudos do texto e do discurso com base sistêmica. A obra historicamente mais importante dessa frente é, sem dúvida, Halliday e Hasan (1976), mas hoje Martin (1992), Martin e White (2005) e Martin e Rose (2007) são provavelmente as referências que desenvolvem com maior refinamento os recursos sistêmicos para análise de textos. Essa frente está em íntimo contato com os estudos críticos do discurso (FAIRCLOUGH, 2003) e é possivelmente a mais difundida no Brasil - ver, por exemplo, os trabalhos de Segundo (2014), de Resende e Ramalho (2006) e em Batista Jr., Sato e Melo (2018).

3) Estudos aplicados de base sistêmica, especialmente no âmbito do ensino de línguas (HALLIDAY, 1993) e nos estudos da tradução (HALLIDAY, 2001). No Brasil, ambos os campos têm expressividade - ver, por exemplo, Silva (2012) sobre educação e Pagano (2008) sobre os estudos da tradução.

O estudo apresentado neste artigo se insere na primeira frente, já que trata da descrição "pura" de parte do estrato semântico do PB. Entretanto, embora não desenvolvamos aqui tal aspecto, o que apresentaremos é potencialmente útil tanto para a análise do discurso como para os estudos aplicados - em consonância com o fato de a aplicabilidade ser um fundamento da Teoria Sistêmico-Funcional (cf. MATTHIESSEN, 2012). Antes de tudo, porém, esboçaremos alguns dos fundamentos da LSF que têm maior impacto sobre a proposta que lançamos no centro do artigo: os conceitos de realização, instanciação e rede sistêmica ${ }^{3}$.

\footnotetext{
3 O "esboço" que faremos a seguir não é metafórico: supomos que o leitor já conhece a maior parte dos conceitos apresentados. Para uma introdução mais aprofundada sobre os fundamentos da LSF, recomendamos a obra de Thompson (2014); em português, recomenda-se a consulta a Gouveia (2009) e a Fuzer e Cabral (2014). A obra de referência avançada mais atualizada em LSF é a de Halliday e Matthiessen (2014).
} 
- | A semântica das perguntas em português brasileiro: uma proposta sistêmico-funcional

\section{Realização}

Baseando-se nos estudos seminais de Hjelmslev (2013 [1943]), a LSF propõe que o sistema linguístico está fundamentalmente estratificado em dois planos: de conteúdo e de expressão. É crucial, porém, no modelo sistêmico-funcional, o fato de que o plano de conteúdo é, em si, estratificado em dois planos: a semântica e, entre ela e a expressão (fonologia/fonética), a lexicogramática. Além do plano linguístico e de sua estratificação interna (semântica, lexicogramática e fonologia/fonética) há, ainda, o plano de contexto, "acima" da semântica.

A relação fundamental entre os estratos é a de realização: o contexto é realizado pela semântica, enquanto a semântica é realizada pela lexicogramática e esta, por sua vez, é realizada pela fonologia, que enfim se realiza na fonética - ver Figura 1. Disso decorre o fato de que, na LSF, há uma certa "subordinação" do sistema linguístico ao contexto (seja cultural, no nível do sistema; seja situacional, no nível da instância - ver seção 2.2), evidenciando o profundo entrelaçamento entre língua e sociedade; e, para continuar usando uma metáfora de poder, o componente que "comanda" a linguagem é a semântica ${ }^{4}$ : a língua, como sistema, é um potencial de significação; o texto, como instância, é um todo significativo ${ }^{5}$.

Figura 1. Hierarquia de Realização

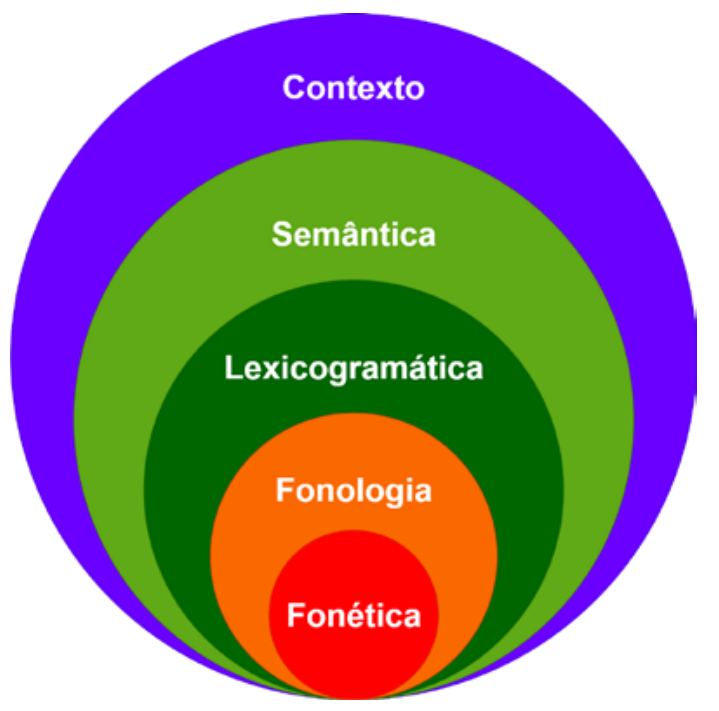

Fonte: Adaptado de Halliday e Matthiessen (2014, p. 26)

\footnotetext{
4 Note-se que, no modelo sistêmico-funcional, como não seria possível uma semântica descontextualizada, não há divisão entre semântica e pragmática; entretanto, muitos dos fenômenos tradicionalmente tratados como pragmáticos são abordados como fenômenos semântico(-discursivos) interpessoais (cf. BATEMAN, 2017; MARTIN, 1992).

5 O modelo de Martin (1992) propõe uma estratificação do plano de contexto (em situacional e cultural) que não adotamos por razões que serão discutidas na sequência. Entretanto, a descrição que propomos ao longo deste artigo não é incompatível com o modelo martiniano (cf. considerações finais).
} 
No nível do texto, o modelo de realização da LSF dá conta, por exemplo, do seguinte cenário: durante uma aula de língua portuguesa, um professor enuncia a seguinte declaração: "o verbo concorda com o sujeito". Então, um aluno que não viera à aula anterior pergunta: "Mas quem é o sujeito?". Quando se profere tal enunciado, segundo a hierarquia de realização, ocorreu o seguinte procedimento atrelado à metafunção interpessoal (ver sobre metafunções ao fim da seção):

1) Contexto: desconhecimento por parte do aluno; conhecimento por parte do professor (RELAÇÕES de desigualdade epistêmica - saber vs. não saber);

2) Semântica: para suprir o desbalanceamento local de conhecimentos, opta-se pela função discursiva de demanda de informação - uma pergunta;

3) Lexicogramática: a realização direta (ou congruente) de uma demanda de informação em português que busca uma informação específica - no caso, um "quem" - é uma pergunta "qu-" (também conhecida como "elemental" ou "aberta"), uma das opções do sistema interpessoal de MODO (cf. FIGUEREDO, 2011, p. 240) em PB;

4) No plano de expressão, sistemas fonético-fonológicos dão realidade física à pergunta em questão, incluindo sua entoação característica.

Este artigo procura especificar quais tipos de demanda de informação estão disponíveis em PB. Para isso, partiremos da interpretação hasaniana do sistema proposto por Halliday (1984) denominado SPEECH FUNCTIONS (FUNÇÕES DISCURSIVAS) - cf. seção 3 -, tentando entender como o potencial de significação do PB forma oposições semânticas delicadas para demandar informação.

Note-se que, no exemplo acima, houve uma correlação entre o parâmetro contextual de RELAÇÕES, o sistema semântico de FUNÇÕES DISCURSIVAS e o sistema lexicogramatical de MODo. Isso se deve ao fato de que esses três elementos dizem respeito à natureza interativa da linguagem: as RELAÇÕES (tenor, em inglês) que se estabelecem culturalmente têm ressonâncias com sistemas semânticos interpessoais (entre os quais está o de FUNÇõES DISCURSIVAS), que, por sua vez, realizam-se nos sistemas lexicogramaticais interpessoais, dos quais o mais importante é o de MODo. Em síntese (com " $\rightarrow$ " significando "são realizadas por"):

$$
\text { RELAÇÕES } \rightarrow \text { FUNÇÕES DISCURSIVAS } \rightarrow \text { MODO }
$$

Tal natureza interativa da linguagem constitui, segundo a LSF, a metafunção interpessoal; é essa metafunção que está em foco neste trabalho. Há, porém, outras duas 
- | A semântica das perguntas em português brasileiro: uma proposta sistêmico-funcional

metafunções: a ideacional, que lida com a construção de experiências e sua articulação; e a textual, que trata do modo como a língua possibilita a instanciação de todos significativos (meaningful wholes) - os textos. É por postular essas três metafunções que a LSF afirma que o sistema linguístico é metafuncionalmente regulado.

\section{Instanciação}

O exemplo dado acima se refere à realização de um contexto de situação em um texto. Entretanto, não há somente a realização do contexto de situação pelo texto: há também a realização do contexto de cultura pelo sistema linguístico - que, na LSF, é entendido como um potencial de significação (meaning potential). A relação entre o potencial (sistema) e a instância (texto) é explicitada pela Escala de Instanciação (Figura 2), indo do potencial até a instância e, nesse percurso, passando pelos registros, compreendidos como subpotenciais - ou, mais especificamente, potenciais que realizam "tipos" de contexto.

Figura 2. Escala de Instanciação

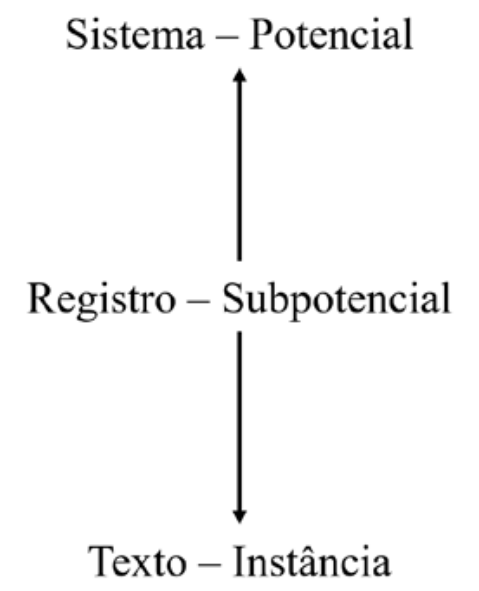

Fonte: Adaptado de Halliday e Matthiessen (2014, p. 28)

É importante ressaltar que, embora algumas interpretações da Teoria SistêmicoFuncional vejam registros como parte do estrato do contexto (MARTIN, 1992), instanciação e realização não são a mesma escala. Cada estrato (contexto, semântica, lexicogramática, etc.) tem seu potencial e, em uma instância, encontramos o resultado da instanciação contextual, semântica, lexicogramatical, etc. Por isso, uma visão mais nuançada e completa da visão sistêmico-funcional sobre a linguagem é a representada na Figura 3, em que realização e instanciação são combinadas, formando uma espécie de "mapa semiótico" (cf. MATTHIESSEN, 2015). Ressaltamos que, na Figura 3, embora os círculos em verde 
se refiram a "língua", "registro" e "texto" como se fossem entidades homogêneas, cada um de tais círculos é decomponível nos estratos expostos na seção acima (semântica, lexicogramática, fonologia e fonética).

Note-se: assim como o texto é uma instância da língua (sistema), um contexto de situação é compreendido, nessa perspectiva, como uma instância da cultura.

Figura 3. A matriz de realização e instanciação

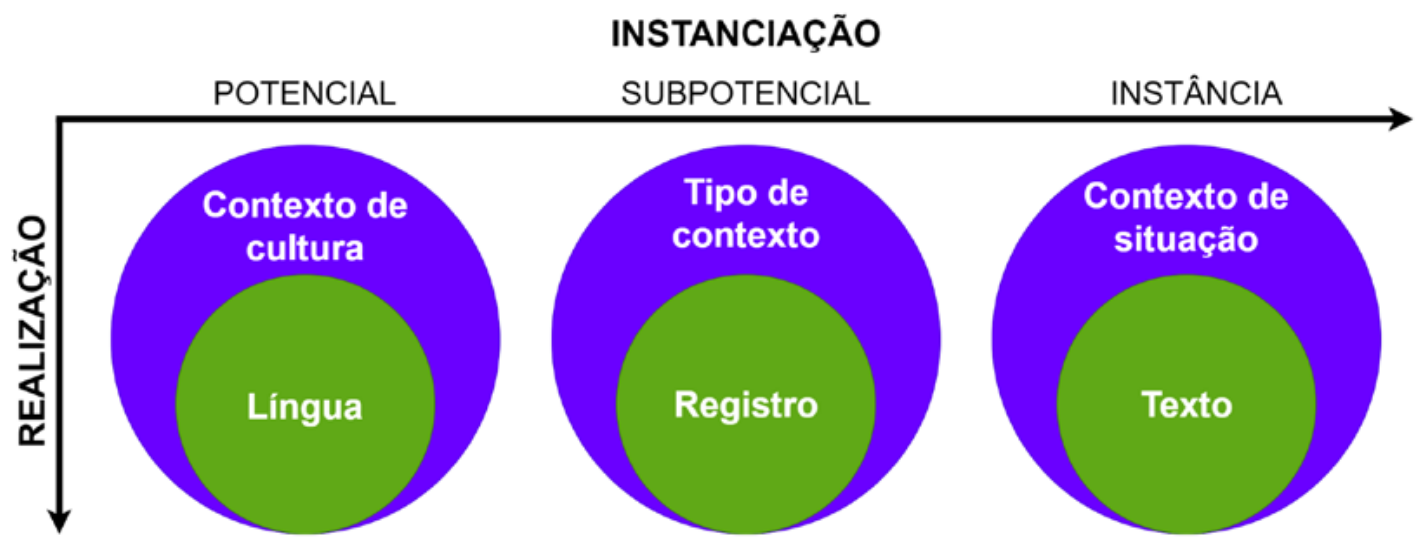

Fonte: Elaboração própria com base em Matthiessen (2015, p. 23)

Este estudo, por ter como objetivo a descrição do PB como potencial, trata da semântica como sistema. Porém, como a LSF postula que há uma complementaridade primordial entre potencial e instância, nossa proposta é fundamentada por exemplos de instanciação genuína das categorias propostas. Esses exemplos provêm, em grande parte, de ocorrências encontradas na internet - mais especificamente, do Twitter, plataforma muito útil para coleta de corpus justamente por ser "pesquisável" ${ }^{6}$.

\section{Rede sistêmica}

Ao compreender um sistema linguístico como um potencial de significação, a LSF também postula que a melhor maneira de descrever as possibilidades linguísticas que se apresentam aos falantes (em cada um dos estratos) é por meio de redes sistêmicas (system networks) - por vezes chamadas simplesmente "sistemas" ou "redes". Tais redes representam o potencial como uma série de escolhas que são feitas ao longo de um "caminho". Por exemplo, no sistema lexicogramatical de MODO, a primeira escolha é entre indicativo e imperativo; se o escolhido for indicativo - caracterizado, em PB, pela

6 Por respeito à privacidade dos usuários, não indicamos as fontes dos tweets. Porém, caso o leitor queira verificar sua autenticidade, todos os exemplos são públicos e podem ser pesquisados na plataforma. 
- | A semântica das perguntas em português brasileiro: uma proposta sistêmico-funcional

presença de um verbo Finito (FIGUEREDO, 2011) -, tem de se escolher entre declarativo e interrogativo, e assim por diante. Quanto mais escolhas são feitas, mais delicada é a descrição.

Há uma série de convenções utilizadas para a representação das redes sistêmicas (cf. HASAN, 2013, 2014). Apresentamos, na Figura 4, um exemplo genérico de uma rede que utiliza as convenções empregadas na descrição das demandas de informação em português.

Figura 4. Convenções básicas para uma rede sistêmica

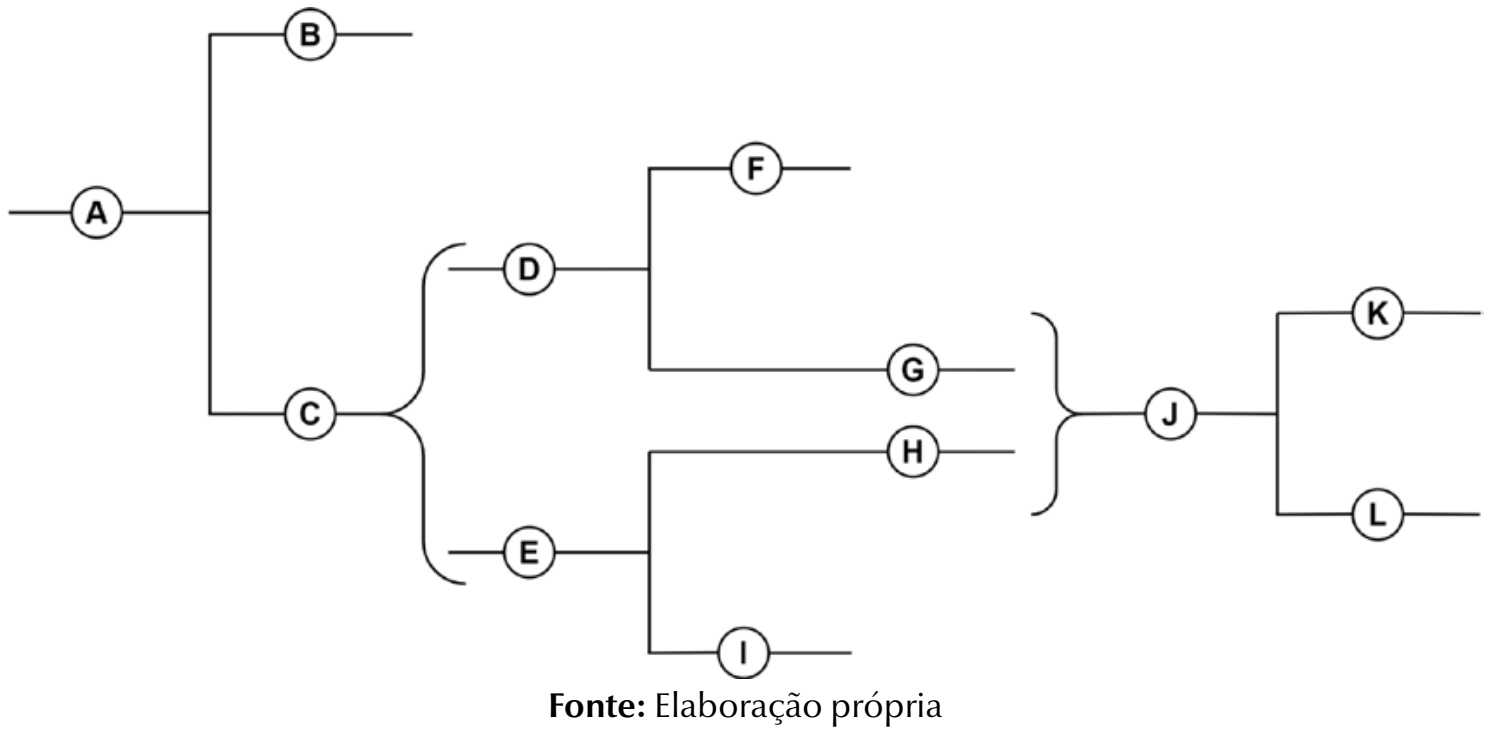

A rede em questão é iniciada quando se tem o elemento A. A partir de tal ponto, deve-se escolher entre B ou C: o colchete virado para a direita - [ - indica justamente que se tem uma relação de alternativa: ou $\mathrm{B}$, ou $\mathrm{C}$. Se a escolha for $\mathrm{C}$, há então uma chave virada para a direita - $\{$ - indicando que dois sistemas, $\mathrm{D}$ e $\mathrm{E}$, "correm em paralelo" - isto é, são simultâneos. Assim, após escolher $\mathrm{C}$, deve-se escolher entre $\mathrm{F}$ e $\mathrm{G}$ e, ao mesmo tempo, entre $\mathrm{H}$ e I. Se as escolhas feitas forem $\mathrm{F} / \mathrm{I}, \mathrm{F} / \mathrm{H}$ ou $\mathrm{G} / \mathrm{I}$, termina-se o "caminho sistêmico". Entretanto, se forem escolhidos $\mathrm{G}$ e H, tem-se acesso ao sistema J. Essa dupla condição de entrada é indicada pela chave virada para a esquerda - \}.

\section{A semântica da mensagem hasaniana}

Embora a descrição de redes sistêmicas lexicogramaticais seja a contribuição mais conhecida da LSF, desde a década de 1970 há esforços para estabelecer sistemas que, embora estejam no plano de conteúdo, não são lexicogramaticais. No início, tratava-se de estudos que focavam em sistemas ativados em contextos específicos: por 
exemplo, Halliday (1973) propõe sistemas de "aviso" e "ameaça" que estariam disponíveis especificamente no contexto de controle materno. A partir dos anos 1980, entretanto, começam a se estabelecer alguns projetos que pretendem descrever, de fato, todo o potencial semântico de uma língua. O mais conhecido desses projetos é, provavelmente, o de J. R. Martin, que foca em significados acima do nível das orações - trata-se de uma semântica discursiva (MARTIN, 1992; MARTIN; ROSE, 2007; MARTIN, WHITE, 2005). É nessa abordagem que se propôs o sistema de AVALIATIVIDADE, um dos mais utilizados no campo dos estudos do discurso.

Há também, porém, a proposta de Ruqaiya Hasan (1983, 1985, 1989) para uma semântica da mensagem. Embora não ignore o fato de que, na LSF, a unidade semântica mais fundamental seja o texto, como apontado pela proposta de Martin, Hasan propõe que a semântica também pode fornecer descrições úteis no nível da oração - já que, segundo sua proposta, mensagem é "a unidade semântica [...] lexicogramaticalmente realizada como a unidade 'oração'" (HASAN et al., 2007, p. 712, tradução nossa).

Nessa perspectiva, a semântica da mensagem é organizada seguindo as três metafunções (ou quatro, se considerarmos a divisão da metafunção ideacional em experiencial e lógica), resultando nos seguintes sistemas: ADOÇÃO DE RELAÇÕES (metafunção interpessoal); cONTINUAÇÃO (metafunção textual); AMPLIFICAÇÃ̃o (metafunção lógica) e CLASSIFICAÇÃo (metafunção experiencial) (cf. HASAN, 2013).

Embora a descrição de todos esses sistemas possa ser oportuna mesmo em estudos aplicados (cf. WILLIAMS, 1994), o sistema da semântica da mensagem que mais recebeu atenção, tanto de Hasan quanto de outros pesquisadores, é o de ADOÇÃO DE RELAÇÕES (cf. LUKIN, 2012; HASAN, 1989, 2013), sendo mesmo o primeiro sistema de semântica da mensagem a ser descrito para além do inglês - Fung (2016) descreve como um sistema análogo se configura em cantonês.

Não é acidental que o sistema tenha recebido tanta atenção: na realidade, trata-se simplesmente da interpretação hasaniana do sistema semântico proposto por Halliday (1984) com o nome de FUnÇÕES DISCURSIVAS. Como a essência do sistema é mantida na interpretação de Hasan, preferimos, neste estudo, utilizar a denominação original de Halliday, embora os resultados a seguir apresentados devam muito às reflexões de Hasan. 
- | A semântica das perguntas em português brasileiro: uma proposta sistêmico-funcional

O sistema de FUNÇÕES DISCURSIVAS introduz dois subsistemas simultâneos ${ }^{7}$ : o papel que o falante assume, seja de fornecer/dar (giving), seja de demandar (demanding); e o valor (commodity) que é colocado em troca: informação - ou seja, um valor verbal ou bens-e-serviços, que poderiam ser parafraseados como "produtos e processos não verbais". A combinação dos dois sistemas resulta em quatro funções discursivas básicas que, como indica Taverniers (2011), são a interpretação sistêmico-funcional de quais seriam os atos de fala (AUSTIN, 1962) menos delicados. As quatro funções discursivas fundamentais são expostas na Figura 5 e, com exemplos, no Quadro 1.

Figura 5. O sistema básico de FUNÇÕES DISCURSIVAS

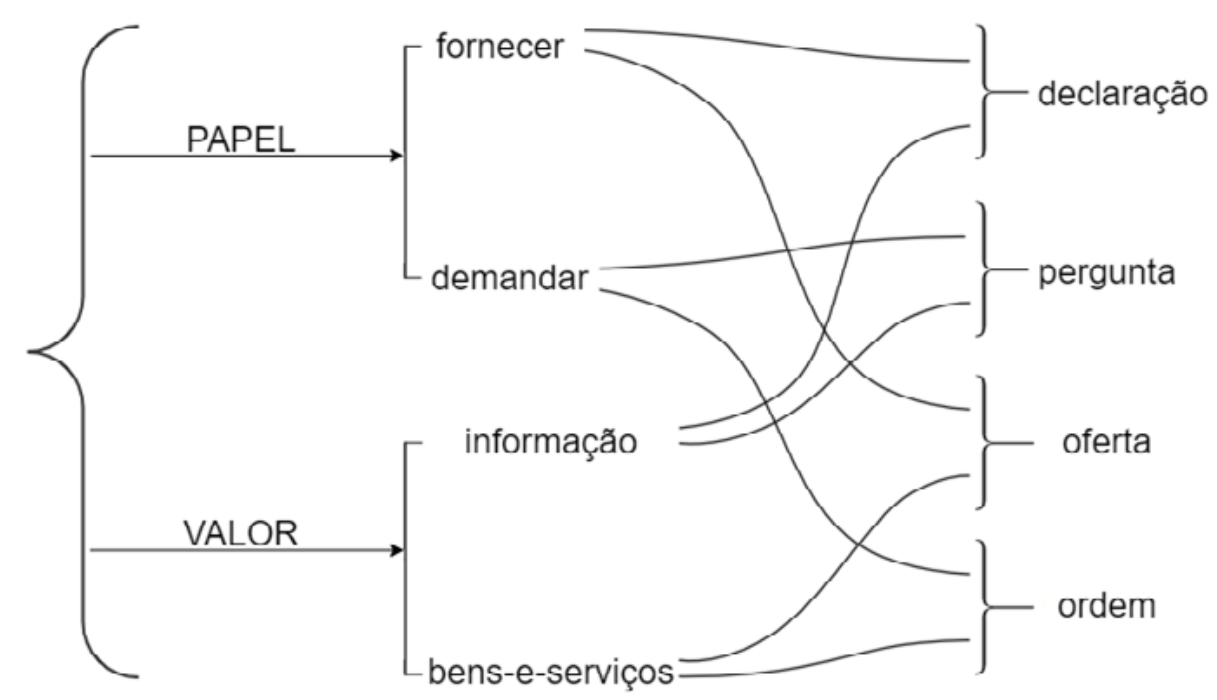

Fonte: Adaptado de Halliday e Matthiessen (2014, p. 136)

Quadro 1. As quatro funções discursivas e exemplos

\begin{tabular}{|c|c|c|c|}
\hline Papel & Valor & Informação & Bens-e-serviços \\
\hline Fornecer & & $\begin{array}{l}\text { Declaração } \\
\text { Tô indo pra casa. }\end{array}$ & $\begin{array}{l}\text { Oferta } \\
\text { Que tal um cafezinho? }\end{array}$ \\
\hline Demandar & & $\begin{array}{l}\text { Pergunta } \\
\text { Você vai pra casa? }\end{array}$ & $\begin{array}{l}\text { Ordem } \\
\text { Vai pra casa! }\end{array}$ \\
\hline
\end{tabular}

Fonte: Elaboração própria

7 Na realidade, há também o subsistema simultâneo de MOVIMENTO, em que se deve escolher entre "iniciar" ou "responder" (HALLIDAY; MATTHIESSEN, 2014, p. 136). Como - seguindo Hasan et al. (2005) - consideramos que a essência de uma pergunta está em demandar uma informação, independentemente de ser em resposta a algo ou não, deixamos de lado as distinções de movimento para a caracterização de perguntas; todavia, uma abordagem exaustiva do sistema de FUNÇÕES DISCURSIVAS teria de levá-lo em consideração. 
Ofertas e ordens são agrupadas na macrocategoria propostas; perguntas e declarações, em proposições. Em PB, assim como em inglês, três das funções têm realizações congruentes no sistema lexicogramatical de MODO - ou seja, há recursos lexicogramaticais especializados em sua realização (cf. FIGUEREDO, 2011): declarações (fornecimentos de informação) são realizadas pelo modo declarativo, que em português é caracterizado pelo movimento tônico de queda; perguntas (demandas de informação) são realizadas pelo modo interrogativo, que em português é caracterizado por um movimento tônico de subida ou pela presença de um elemento "qu-"; ordens (demandas de bens-e-serviços) são realizadas pelo modo imperativo, que em PB é caracterizado pela ausência de Finito (FIGUEREDO, 2011). Ofertas - fornecimentos de bens-e-serviços tendem a não desenvolver um modo lexicogramatical de realização, mas em PB costumam ser realizadas por orações interrogativas (com auxílio, por exemplo, da construção "que tal") ou imperativas.

É possível, porém, que uma função com realização congruente seja realizada incongruentemente. Por exemplo, pode-se dar uma ordem utilizando o modo interrogativo: "Você pode abrir as janelas?". A relação de incongruência entre uma escolha semântica e uma lexicogramatical é denominada, na LSF, metáfora gramatical. No caso dado, seria, especificamente, uma metáfora gramatical interpessoal - fenômeno compreendido na Pragmática dos Atos de Fala como "atos de fala indiretos" (SEARLE, 1969).

Tendo tais considerações fundamentais em mente, cabe explicitar qual região do sistema de FUNÇÕES DISCURSIVAS pretendemos explorar neste artigo:

1) buscaremos desenvolver uma descrição mais delicada para as opções de pergunta - ou seja, de demanda de informação - em PB;

2) porém, não levaremos em conta as relações incongruentes entre semântica e lexicogramática, pois isso nos obrigaria a uma consideração muito mais ampla sobre as opções de FUNÇÕES DISCURSIVAS disponíveis em PB, algo que foge ao escopo deste estudo;

3) indicaremos, todavia, quais as realizações lexicogramaticais mais típicas - ou seja, congruentes - para cada opção semântica de demanda de informação. Para isso, partimos da descrição que Figueredo (2011) faz dos recursos interpessoais na lexicogramática do PB.

Seria possível questionar, neste ponto, a necessidade de uma semântica interpessoal que diga respeito a uma maior delicadeza no sistema de FUNÇÕES DISCURSIVAS - a empreitada 
- | A semântica das perguntas em português brasileiro: uma proposta sistêmico-funcional

que assumimos aqui. De fato, se a lexicogramática proposta pela LSF já tem um fundamento semântico e as opções do sistema de MODO, que realizam as FUNÇÕES DISCURSIVAS, já foram descritas detalhadamente para o PB (FIGUEREDO, 2011), por que propor mais um sistema que diz respeito à análise de enunciados em termos de seus significados interpessoais? Trata-se de um questionamento válido; oferecemos três respostas:

1) Um primeiro ponto é que a LSF de fato propõe o estrato da semântica e não há motivo para supor que os sistemas semânticos sejam mais simples do que os lexicogramaticais (embora talvez se tenha tal impressão ao compararmos o sistema de FUNÇÕES DISCURSIVAS Com o de MODO em Halliday e Matthiessen (2014) - lembremo-nos, porém, de que tal obra tem como foco a lexicogramática, não a semântica).

2) Uma segunda reflexão é que um sistema semântico como o que propomos é em princípio mais sensível a diferenças de significado do que a lexicogramática, que, por mais funcional que seja, precisa se ater a distinções formais básicas, apresenta certas limitações em termos de exploração semântica ${ }^{8}$.

3) Finalmente, a abordagem topológica para demandas de informação que propomos ao fim do artigo é algo que, no nosso conhecimento, é inédito para a semântica/pragmática do $\mathrm{PB}$, além de mostrar as possíveis contribuições da LSF a abordagens "graduais" (não discretas) para a descrição e análise de atos de fala.

O procedimento metodológico que fundamenta nossa proposta tem duas bases. Em primeiro lugar, como o desenvolvimento "canônico" da delicadeza do sistema de FUNÇÕES DisCursivas é o de Hasan (1989, 2013), que tem como objeto o inglês (especialmente australiano) e foi consolidado ao longo de décadas, inicialmente o utilizamos como modelo básico e verificamos em que medida as opções para o inglês eram consistentes com as do português. Evidentemente, as diferenças são muitas e, por isso, o sistema aqui proposto não é mera "tradução" do original inglês - ao contrário, há várias distinções fundamentais; entretanto, diversas considerações feitas por Hasan, como a questão da "antecipação" de resposta, foram importantes para o desenvolvimento do nosso sistema.

Além disso, também seguimos a perspectiva trinocular preconizada pela LSF (cf. HALLIDAY, 2009): ao explorarmos a semântica, temos de observá-la (1) "de cima": no

8 Por exemplo, Halliday (1994, p. XIX, tradução nossa) escreve o seguinte sobre a diferença entre semântica e gramática: "todas as categorias empregadas [na descrição lexicogramatical] devem estar claramente 'lá' na gramática da língua. Elas não são estabelecidas simplesmente para rotular diferenças semânticas". 
caso, com quais aspectos do contexto cada opção pode se relacionar; (2) "de baixo": quais as realizações gramaticais congruentes para as opções; e (3) "ao redor": de que modo o sistema em questão se relaciona com outros sistemas e subsistemas do mesmo estrato (semântica). Devemos ressaltar, porém, que, embora por vezes teçamos comentários sobre possíveis motivações contextuais para cada opção, nossa proposta destaca os pontos de vista "de baixo", observando as realizações lexicogramaticais congruentes para cada opção (embora não de uma maneira exaustiva), e, especialmente, "ao redor", considerando de que modo as opções se relacionam com outros subsistemas de FUNÇõES DISCURSIVAS - esta última perspectiva é especialmente evidenciada por nossa proposta topológica (seção 4.2).

Ademais, note-se que, como pretendemos apresentar uma descrição detalhada das possibilidades de demandas de informação em português brasileiro, sem considerar tal demanda como a parte inicial do par dialógico pergunta-resposta, nosso estudo se distancia daquele de Fávero, Andrade e Aquino (2015), que compreende a pergunta não como a função discursiva de demandar informação (embora a reconheçam como uma de suas funções mais típicas), mas como justamente a primeira etapa no par perguntaresposta. Nesse sentido, a proposta das autoras se aproxima do sistema de NEGOCIAÇÃo proposto por Martin (1992).

Também não trataremos das chamadas "perguntas retóricas" porque, na realidade, tais enunciados estão mais próximos de declarações (fornecimento de informação), já que supõem um acordo com um ouvinte em relação à resposta esperada, não havendo, de fato, uma demanda.

\section{A semântica das demandas de informação do português brasileiro}

\section{A rede sistêmica de DEMANDAS DE INFORMAÇÃo}

A rede sistêmica de DEMANDA DE INFORMAÇÃO para o PB está exposta na Figura 6. 
- | A semântica das perguntas em português brasileiro: uma proposta sistêmico-funcional

Figura 6. Sistema semântico de DEMANDA DE INFORMAÇÃO em português brasileiro

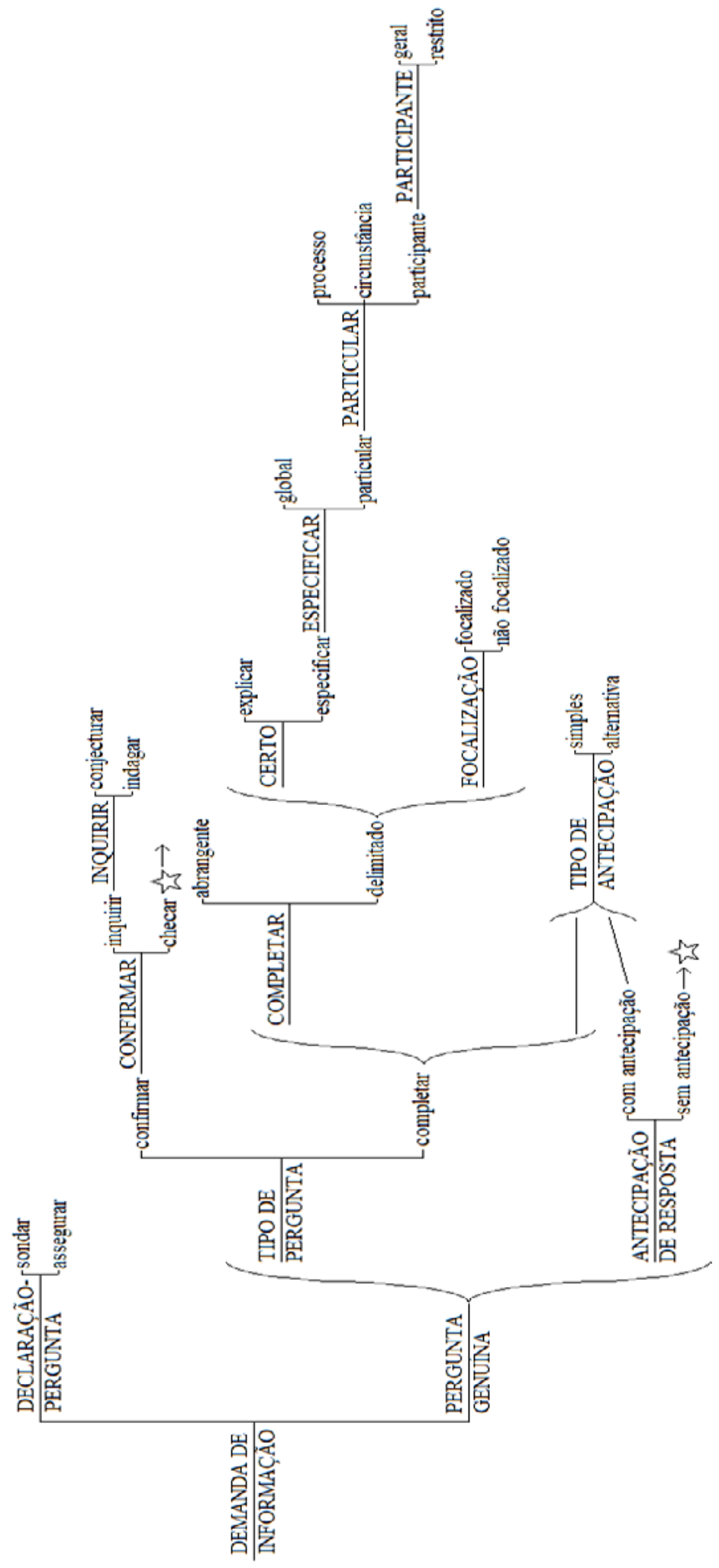

Fonte: Elaboração própria 
A partir do momento em que, no sistema de FUNÇÕES DISCURSIVAS, selecionam-se "demandar" e "informação", começam as escolhas no sistema em questão. A distinção menos delicada é a entre "perguntas genuínas" e "declarações-pergunta"; estas, como seu nome indica, embora tenham um traço "demandante", estão fortemente relacionadas a outra função discursiva - a declaração. Trata-se de declarações que, após o fornecimento de informações, colocam a polaridade da oração - e, portanto, sua validade - em questionamento, o que em algumas interações pode ser interpretado como, de fato, uma demanda de informação. Há dois subtipos para declarações-pergunta: "sondar" e "assegurar".

A opção "sondar" é tipicamente realizada por uma oração declarativa - ou seja, com movimento tônico descendente - seguida pela partícula modal "né?" (ou, em casos mais raros, "não?") com movimento tônico ascendente (ou, na escrita, seguida de ponto de interrogação). Exemplo (SÁ et al., 2017, p. 103, ênfase nossa):

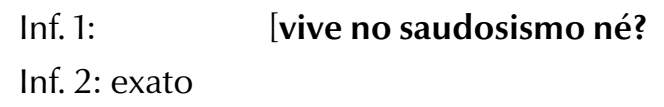

Nota-se que, aparentemente, o demandante assume como resposta algo em plena compatibilidade com o que inicialmente declara. A partícula "né" parece simplesmente pedir uma validação por parte do outro interactante.

Já "assegurar" é congruentemente realizada pelo subtipo de oração declarativa que, nos termos de Figueredo (2011), tem ao seu fim uma Pergunta-Finito - isto é, o Finito é repetido com a polaridade inversa à da oração. Exemplo (retirado do Twitter; destaque nosso):

\section{(2) Você já foi lá, não foi? [...]}

[Resposta]: não, esse é o flex [...]

Neste caso, o demandante parece, de alguma forma, ter uma expectativa de que, considerando o que se conhece sobre o outro, a resposta será compatível com o que está sendo declarado; não há, porém, total certeza, motivando a Pergunta-Finito.

Vê-se pelos exemplos que, embora tais opções tenham um "núcleo declarativo", elas estão num ponto intermediário entre "declarações genuínas" e "perguntas genuínas". Isso motivou sua inclusão no sistema, embora em uma posição periférica.

9 Consideramos, com Figueredo (2011), que partículas modais são (em grande parte) aquilo que tradicionalmente se classifica como "marcadores discursivos". Além disso, Figueredo (2011) considera-as parte do sistema lexicogramatical de AVALIAÇÃO MODAL, que por sua vez realizaria parte dos significados do sistema semântico-discursivo de ENGAJAMENTO (cf. FIGUEREDO, 2011, p. 229). Embora tal interpretação possa ser frutífera, não a adotamos neste estudo. 
- A semântica das perguntas em português brasileiro: uma proposta sistêmico-funcional

Caso a escolha inicial seja "perguntas genuínas", tem-se acesso a dois sistemas simultâneos. Vamos nos deter agora no TIPO DE PERGUNTA ${ }^{10}$. Há duas possibilidades: perguntas do tipo "confirmar" e do tipo "informar". Se a escolha for "confirmar", abrese a possibilidade de fazer perguntas sobre a validade de algo - ou seja, sobre sua correspondência (ou discrepância) com a realidade. Essas demandas de informação são congruentemente realizadas por orações interrogativas polares, também conhecidas como interrogativas de "sim/não" ou "fechadas" (FÁVERO; ANDRADE; AQUINO, 2015). Segundo Figueredo (2011), em PB essas interrogativas são caracterizadas por um movimento tônico ascendente.

As perguntas de "confirmar" podem ser do tipo "inquirir" ou "checar". O traço típico de "checar" é a inclusão, ao fim da demanda de informação, da partícula modal "é?". Veja que, ao contrário das declarações-pergunta, nesse caso, embora haja um elemento final que lide com a polaridade da proposição, todo o movimento tônico é ascendente, indicando a maior "autenticidade" interrogativa. Mais semanticamente relevante do que isso, porém, é o fato de a partícula "é?" ser especializada justamente em negociar confirmações (FIGUEREDO, 2011). Veja-se o exemplo retirado de Figueredo (2011, p. 227, ênfase nossa):

(3) $-[\ldots]$ você grava as minhas aulas, é?

- Gravo

A partícula "é?" ressalta a natureza "confirmativa" da pergunta, recebendo uma resposta que fornece, justamente, a polaridade indagada ("Gravo"). Além disso, tal partícula parece indicar que a informação negociada é inesperada; em (3), por exemplo, quem faz a pergunta é um docente que aparentemente se surpreendeu ao perceber que alguém gravava suas aulas - o que o levou, justamente, a checar tal informação.

Observe-se que, na Figura 6, há, ao lado da opção "checar", uma estrela seguida de uma seta para a direita; esses símbolos são repetidos sob a opção "sem antecipação" no sistema de ANTECIPAÇÃO DE RESPOSTA. Isso indica que, sempre que se escolhe a opção "checar", é obrigatório escolher "sem antecipação". Voltaremos a isso quando abordarmos especificamente as antecipações de resposta.

10 Não incluímos, no sistema de DEMANDA DE INFORMAÇÃO, distinções de polaridade. Uma pergunta e sua "versão" de polaridade oposta são categorizadas igualmente. Isso se justifica porque o sistema de FUNÇõES DISCURSIVAS não aborda diretamente fenômenos ligados ao comprometimento do falante com o que enuncia - o que envolve, evidentemente, a polaridade; tais questões são mais bem tratadas, por exemplo, no sistema semântico-discursivo de ENGAJAMENTO, proposto por Martin e White (2005). Entretanto, deve-se notar que, quando se enuncia uma pergunta com polaridade negativa, o demandante parece assumir que o respondente faria o contrário ao enunciado: em "você não foi à praia?", pode-se inferir que, na perspectiva do demandante, o respondente "deveria" ter ido à praia. Tais efeitos de sentido são relevantes e merecem atenção, mas estão fora do escopo deste estudo. 
Caso "checar" não seja selecionado, a opção "inquirir" dá duas possibilidades de pergunta em que não se utiliza a partícula "é?". Uma opção, "indagar", diz respeito a perguntas polares "básicas", que simplesmente questionam a validade da proposição. Por exemplo (do Twitter): amg esse livro me perturba até hoje, você já terminou? [Resposta:] terminei sim amg!!

Há, porém, uma opção de "inquirir" que, além de questionar a validade da proposição, acrescenta um traço de "hipótese", indicando menor compromisso epistêmico com a possibilidade de a resposta ser "sim". O recurso típico para indicar tais perguntas de "conjecturar" é a introdução da construção interrogativa "será que" no início do enunciado. Exemplo (retirado do Twitter):

(5) Será que Camilla tá falando dos agros?

Tal construção é um resquício do uso do futuro do presente para indicar baixa modalidade epistêmica - enquanto, atualmente, em PB, é mais comum utilizar, para tais efeitos, o futuro do pretérito ou mesmo o pretérito imperfeito. De fato, o exemplo acima poderia ser reformulado como "Estaria Camilla falando dos agros?" e o traço de "conjecturar" seria mantido, embora nesse caso provavelmente haveria conotações de maior formalidade. Deve-se tomar cuidado, porém, com instâncias da construção "será que": embora lexicogramaticalmente tal construção ocorra com orações interrogativas, nem sempre tais orações realizam perguntas; muitas vezes, ao contrário, trata-se de declarações incongruentes que usam a construção para apontar, justamente, a baixa modalidade (no exemplo a seguir, retirado do Twitter - "Será que ele sabe o quanto eu amo ele?" -, não há de fato uma demanda, mas um "lançamento de hipótese").

Tratemos agora das opções sob o subsistema de "completar", que se opõe a "confirmar". Enquanto as possibilidades confirmativas tratam de demandas sobre a validade da proposição, sendo congruentemente realizadas por interrogativas polares, perguntas completivas abordam não a validade da proposição, mas "lacunas" na proposição que o enunciador pede que o coenunciador "preencha". Quase todas as opções de "completar" se realizam congruentemente a partir de interrogativas "qu-", também conhecidas como "elementais" ou "abertas".

Demandas completivas podem ser do tipo "abrangente" ou "delimitado". No primeiro caso, o enunciador simplesmente propõe um tópico discursivo (JUBRAN, 2015) sobre o qual quer saber mais informações, com poucas especificações. Por isso, é a única opção completiva que é congruentemente realizada por orações menores - isto 
- | A semântica das perguntas em português brasileiro: uma proposta sistêmico-funcional

é, enunciados em que não há um Predicador ou um Finito (HALLIDAY; MATTHIESSEN, 2014). Em PB, perguntas completivas abrangentes geralmente são realizadas por um grupo nominal definido introduzido pela conjunção aditiva " $\mathrm{e}$ " (e com movimento tônico ascendente ou, na escrita, ponto de interrogação). Em inglês, a construção "what about" realiza uma função muito semelhante (HASAN, 2013). Veja-se o seguinte tweet:

(6) Mas e o menino novinho lá? Ele parece bonzinho

[Resposta:] ah sim, ele parece legal (por enquanto)

Vemos, portanto, que as perguntas "abrangentes", de fato, atuam como introdutoras de um tópico discursivo, sem delimitação exata do seu foco de centração. Usualmente, imagina-se que haja entre o demandante e o respondente conhecimento compartilhado que permita fazer a delimitação. Caso contrário, não é incomum que tais perguntas tenham como resposta uma nova pergunta, análoga a "O que tem isso?", exigindo maior delimitação tópica.

Quando a opção de pergunta completiva é "delimitada", temos opções que são congruentemente realizadas por perguntas "qu-". Há, porém, dois sistemas simultâneos: um que trata precisamente dos tipos de pergunta completiva "delimitada" e outro que lida com a ocorrência ou não de focalização (cf. BRAGA; BARBOSA, 2009; FIGUEREDO, PAGANO, FERREGUETTI, 2014). Mais especificamente, se uma pergunta for focalizada, seu elemento "qu-" é seguido pela conjunção "que" ou por "ser que". Em perguntas, a focalização em geral parece aumentar a pressão do demandante pela completação da resposta, desestimulando uma atitude de não resposta da parte do respondente. Por exemplo (retirado do Twitter; ênfase nossa):

(7) pelo amor de deus onde que você ouviu minha risada?

[Resposta:] em um vídeo que você me mandou, faz tempo...

Todas as opções de perguntas completivas do tipo "delimitado" podem ou não ser focalizadas. Quanto ao tipo de tais perguntas, a primeira divisão é entre perguntas de "explicar", em que se demanda a motivação (causa, explicação, justificativa, etc.) de uma proposição, e "especificar", em que se demanda maior precisão em relação a algum aspecto da proposição: os processos, os participantes ou as circunstâncias. A opção "explicar" é realizada congruentemente pelas construções "por que" e "por qual (motivo, razão, etc.)". Exemplo (proveniente do Twitter):

Por que vc gosta da minha amizade? 
Quando se escolhe "especificar", deve-se escolher entre "global", demandando uma especificação sobre todo um evento, e "particular". A realização mais congruente de perguntas "globais" se faz com a construção "(o) que" e verbos que denotam processos muitos genéricos, na fronteira entre os materiais e os existenciais (HALLIDAY; MATTHIESSEN, 2014), como "acontecer", "ocorrer", "haver" e (informalmente) "rolar". Exemplo (extraído do Twitter):

o que tá acontecendo hein?

[Resposta:] nada

Note-se que, embora tanto perguntas "globais" e "abrangentes" sejam caracterizadas por grande imprecisão, dois aspectos principais justificam sua divisão: 1) perguntas abrangentes são tipicamente realizadas por orações menores (sem verbo), enquanto o foco das globais está justamente em um verbo (que tem "(o) que" como Sujeito); 2) perguntas abrangentes costumam focar em um participante (geralmente realizado por um grupo nominal), ao passo que perguntas globais se caracterizam por se centrarem em um processo genérico, sendo possível, por vezes, a ocorrência de circunstâncias ("o que está acontecendo aqui?").

Quando uma pergunta completiva tem os traços "especificar" e "particular", há três opções possíveis. Em primeiro lugar, pode-se demandar especificação sobre certo processo. Nesses casos, ao contrário das perguntas "globais", costuma haver participantes e adjuntos. O verbo tende a ser bastante genérico, como "fazer" ou "realizar". Exemplo (extraído do Twitter):

$$
\text { Quando a luz acaba de noite oq vc faz? }
$$

[Resposta:] \#eusentonacama [= "eu sento na cama"]

Note-se que a situação é muito bem delimitada por circunstâncias, além de haver um participante especificado ("vc"). O verbo, porém, é "faz", deixando amplo espaço para respostas em relação ao processo.

Se a pergunta demandar circunstâncias, pedem-se especificações sobre o "quando", o "onde" ou o "como" de um evento. Logicamente, a realização congruente de tal opção é uma oração interrogativa "qu-" com uma dessas construções ou, ainda, com locuções como "em que lugar", "de que maneira", etc. Vejamos mais um exemplo retirado do Twitter:

(11) quando você comprou?

[Resposta:] Dia 8 eu acho 
- | A semântica das perguntas em português brasileiro: uma proposta sistêmico-funcional

Finalmente, caso a pergunta peça uma especificação de participantes, há duas possibilidades: geral ou restrito. Se a especificação é restrita, a realização mais congruente é utilizar os pronomes "que" ou "qual(is)" seguidos de um grupo nominal. Por exemplo (retirado do Twitter; ênfase nossa):

$$
\text { eu vejo filme ou leio mangá, no momento estou vendo filme }
$$

[Resposta/Pergunta:] Que filme vc tá vendo? [...]

[Resposta:] tô vendo $\mathrm{x}$ men: confronto final amg

Veja que a pergunta poderia ter sido "O que vc tá vendo?", mas o enunciador, por saber que o objeto de "ver" era um filme, optou por uma especificação restrita, enunciando "que filme". Entretanto, se no primeiro turno o enunciador tivesse escrito que "estou vendo tv", uma pergunta como "O que vc tá vendo?" seria mais apropriada, dada a variedade de programas que podem ser vistos em uma televisão. Perguntas como essa, sem restrições semânticas explícitas, são classificadas como gerais. Um exemplo do Twitter:

$$
\text { o que que vc ta vendo aí? }
$$

[Resposta:] a jisoo"11

Na pergunta em (13), "aí" se refere a uma foto em que uma figura "escondida" podia ser vista. Entretanto, o enunciador de (13) aparentemente não viu a figura, o que o levou a enunciar a pergunta em questão. Caso houvesse visto, mas não identificado a figura, poderia ter escrito "que figura vc tá vendo aí?", optando por uma pergunta restrita. Isso sugere que as categorias aqui apresentadas têm relevância mesmo para estudos em que outros modos semióticos, em conjunção com o verbal, estão sendo investigados.

Finalizamos, assim, a descrição de todos os tipos de pergunta "genuína": confirmativas, completivas e seus subtipos. Descreveremos agora um sistema que é simultâneo a tais tipos e, por isso, pode se combinar com qualquer uma de suas opções (exceto um caso - ver abaixo). Trata-se do sistema de ANTECIPAÇÃo DE RESPOSTA. Como sua denominação indica, tal sistema lida com casos em que ainda se tem uma demanda de informação, mas o enunciador sugere, geralmente ao fim do seu enunciado, quais seriam as respostas mais prováveis. Assim, uma pergunta pode ser "com antecipação" ou "sem antecipação".

Quando perguntas confirmativas (congruentemente realizadas como interrogativas polares) têm antecipação, só há uma possibilidade (ao contrário das perguntas completivas, que podem ter antecipação simples ou alternativa): geralmente com dois grupos nominais coordenados pela conjunção "ou", introduz-se aquilo que o enunciador sugere ser uma

11 Trata-se de uma cantora de K-pop. 
resposta plausível para sua pergunta. Vejamos, por exemplo, o seguinte tweet, em que se instancia uma pergunta confirmativa (do subtipo "indagar") com antecipação:

(14) o sapo joga switch ou pc?

[Resposta:] Switch, um com cores q combinam c ele

O enunciador poderia ter escrito "o que o sapo joga?", instanciando uma pergunta completiva; ou, ainda, "o sapo joga switch?", e assim teríamos uma pergunta confirmativa sem antecipação - que, por isso, poderia ser respondida com "sim" ou "não". Porém, ao utilizar como complemento de "joga" dois grupos nominais coordenados por "ou", o enunciador reduz drasticamente as possibilidades de receber "sim" ou "não" como resposta e leva o respondente a lidar com uma das sugestões coordenadas. Como se verifica pela resposta dada, foi o que de fato ocorreu.

Como mencionamos anteriormente, a opção confirmativa "checar" tem a restrição de nunca poder apresentar antecipação de resposta, o que é indicado pelas estrelas na representação da rede sistêmica. Isso pode ser motivado pelo fato de a partícula "é?" forçar a pergunta a focar somente na polaridade, impossibilitando a antecipação - que sempre tem como alvo participantes, processos ou circunstâncias. Nesse aspecto, perguntas do tipo "checar" são próximas às declarações-pergunta, já que elas também se especializam exclusivamente em colocar em negociação a validade (polaridade e modalidade) das proposições (cf. seção 4.2).

Quando perguntas do tipo "completar" têm antecipação de resposta, há duas possibilidades. Uma é muito semelhante à única opção disponível quando se trata de uma pergunta confirmativa com antecipação: tem-se, ao fim da pergunta, dois grupos (geralmente nominais) coordenados pela conjunção "ou". Vejamos o seguinte tweet:

o que tá acontecendo? Um evento ou algo assim?

Em (15), o enunciador divide seu enunciado em duas partes: a pergunta em si, mais especificamente um caso de demanda completiva global, e a antecipação de resposta em que são coordenados os grupos "Um evento" e "algo assim". Note-se, então, que a "generalidade" da pergunta inicial permanece, mas a antecipação permite que o enunciador sugira respostas possíveis.

Perguntas completivas com antecipação têm, porém, outra possibilidade: uma antecipação "simples", em que não há múltiplas alternativas na resposta sugerida. Essa opção é congruentemente realizada pela colocação, ao fim da pergunta, de um grupo (nominal, verbal, adjetival ou adverbial) ou de um sintagma preposicional. O exemplo (16) é mais um tweet. 
- | A semântica das perguntas em português brasileiro: uma proposta sistêmico-funcional

o q vc tá fazendo? comendo?

Trata-se de uma pergunta completiva em que se pede a especificação de um processo ("fazendo"). O enunciador, porém, já sugere uma resposta. Como só uma possibilidade é sugerida, trata-se de uma antecipação simples. Reiteramos que, enquanto perguntas completivas podem ter antecipação de resposta simples ou alternativa, perguntas confirmativas só podem ter antecipações alternativas - e, por isso, nem chegam a acessar o sistema de TIPO DE ANTECIPAÇÃO. Como mostraremos, porém, o fato de ambas poderem ter antecipações alternativas pode levar a uma aproximação topológica entre perguntas confirmativas e completivas (ver abaixo).

\section{Uma proposta topológica para demandas de informação}

Conforme indicamos ao início da seção 4.1, nem todas as opções apresentadas são genuinamente demandas de informação; aquelas que denominamos "declaraçõespergunta" estão na fronteira entre demandar e fornecer informação - daí seu nome. Isso indica que a semântica interpessoal pode ser entendida não só tipologicamente, com categorias discretas, mas também topologicamente, com diferenças de grau entre cada uma das categorias (cf. MARTIN; MATTHIESSEN, 1991).

Tendo isso em vista, esboçamos na sequência uma possível organização topológica das opções de DEMANDA DE INFORMAÇÃo em PB em termos de dois continua. O primeiro deles abrange o espaço de contato entre fornecer e demandar informação, intersecção essa ocupada pelas "declarações-pergunta". O segundo deles se situa completamente no espaço da demanda de informação e está relacionado à natureza da informação demandada e ao quanto a pergunta restringe as possibilidades de resposta, levando em consideração o subsistema de ANTECIPAÇÃO DE RESPOSTA.

\section{Das declarações às perguntas confirmativas}

O fato de as declarações-pergunta estarem em contato com o sistema de FORNECIMENTO DE INFORMAÇÃO sugere que, para explorarmos o domínio topológico das perguntas, devemos buscar as categorias que, mesmo sendo "perguntas genuínas", têm afinidades com as declarações-pergunta. Uma primeira possibilidade é a opção confirmativa "checar". Trata-se, claramente, de uma possibilidade "exótica" dentro das perguntas genuínas, já que é a única opção que não permite antecipação de resposta. Além disso, como mencionamos anteriormente, tanto as perguntas de "checar" como as declarações-pergunta têm como foco a validade (modalidade e polaridade) da mensagem, 
o que ressalta a afinidade entre as categorias. Desse modo, um primeiro "percurso", vindo das declarações em direção às perguntas, seria o seguinte:

$$
\text { declarações - declarações-pergunta - checar }
$$

Devemos procurar quais são, agora, as opções de perguntas genuínas mais próximas de "checar". Parece-nos evidente que são aquelas sob o sistema de "inquirir": indagar e conjecturar. Em outras palavras: demandas de informação congruentemente realizadas como perguntas polares são as que mais afinidade têm com a opção de pergunta que, por sua vez, é a mais próxima das declarações-pergunta:

$$
\text { declarações - declarações-pergunta - checar-inquirir }
$$

Os critérios para distinguir cada um dos passos no continuum podem ser explicitados da seguinte forma:

- "declaratividade": opções com esse traço têm como propósito primário fornecer informações - perguntas genuínas não podem, portanto, ter tal traço, que engloba as declarações e as declarações-pergunta;

- "questionar validade": indica que a opção em questão, mesmo que tenha o traço de declaratividade, está sendo negociada em termos de polaridade e modalidade;

- "potencial de antecipação": indica que a opção em questão tem acesso ao sistema de ANTECIPAÇÃO DE RESPOSTA.

\begin{tabular}{|c|c|c|c|c|}
\hline & declaratividade & $\begin{array}{l}\text { questionar } \\
\text { validade }\end{array}$ & $\begin{array}{l}\text { potencial de } \\
\text { antecipação }\end{array}$ & Exemplos \\
\hline declarações & + & - & - & $\begin{array}{l}\text { "Você grava as minhas } \\
\text { aulas." }\end{array}$ \\
\hline $\begin{array}{l}\text { declarações- } \\
\text { pergunta }\end{array}$ & + & + & - & $\begin{array}{c}\text { "Você grava as minhas } \\
\text { aulas, né?" }\end{array}$ \\
\hline checar & - & + & - & $\begin{array}{c}\text { "Você grava as minhas } \\
\text { aulas, é?" }\end{array}$ \\
\hline inquirir & - & + & + & $\begin{array}{c}\text { "Você grava as minhas } \\
\text { aulas?" }\end{array}$ \\
\hline
\end{tabular}

Quadro 2. De declarações até "indagar" em termos de "traços"

Fonte: Elaboração própria

Os traços " +" e "-" propostos não devem ser lidos à luz das propostas da semântica estruturalista, mas como uma indicação de quais aspectos distinguem mais marcadamente, num continuum fluido, as opções em questão. Cada opção tem, em princípio, outros traços além dos apresentados aqui. 
- | A semântica das perguntas em português brasileiro: uma proposta sistêmico-funcional

\section{Das perguntas confirmativas às completivas}

Outro continuum identificável está entre perguntas confirmativas e completivas. Tal continuum pode ser construído ao se considerar tanto o acesso de cada tipo de pergunta ao subsistema de ANTECIPAÇÃO DE RESPOSTA e suas respectivas opções quanto os efeitos de tal acesso em termos das restrições de respostas possíveis ao interlocutor, quais sejam, validar, selecionar ou preencher.

Começando com uma pergunta confirmativa como "Vamos para a praia?", em que não há acesso ao subsistema de ANTECIPAÇÃO DE RESPOSTA e o interlocutor é instado a apenas validar (por polaridade ou modalidade) uma única opção (a praia), parece-nos que a opção mais próxima é, curiosamente, uma pergunta completiva, mas com antecipação simples: "Aonde vamos? Para a praia?". A antecipação simples leva a pergunta a negociar, assim como a confirmativa sem antecipação, apenas validade de "nós irmos para a praia"; em outros termos, a resposta pode ser "vamos", "sim", "não", "talvez", etc. Nesse caso, o que vemos é que a antecipação de resposta simples aproxima a completiva da confirmativa.

O próximo passo seria, então, uma confirmativa com antecipação: "Vamos para a praia ou para casa?"12. Aqui, já não se restringe a resposta a uma validação, uma vez que não se espera uma réplica meramente polar ou modal, mas a escolha de uma das alternativas. Estamos, portanto, no espaço da seleção. Em seguida, tem-se uma completiva com antecipação alternativa: "Aonde vamos? Para a praia ou para casa?". Tal caso é tão próximo ao anterior que se pode aventar um alto grau de "sinonímia": os exemplos dados são facilmente intercambiáveis. A opção por considerar a pergunta confirmativa como mais à esquerda do continuum se deve ao fato de a restrição estar construída em uma única estrutura oracional, não requisitando justaposição de unidades informacionais para gerar esse efeito. O último ponto do continuum está, enfim, nas completivas sem antecipação, em que há genuinamente uma demanda por "preenchimento" de lacunas, com maior abertura de resposta: "Aonde vamos?".

O Quadro 3 sintetiza essas distinções em termos de três critérios:

- Restrição de resposta - validar: demanda-se uma validação sobre a proposição em questão em termos de polaridade e/ou modalidade.

- Restrição de resposta - selecionar: demanda-se a seleção de uma alternativa de resposta.

12 Ressaltamos que a antecipação em perguntas confirmativas é sempre alternativa. 
- Restrição de resposta - preencher: demanda-se o preenchimento de um elemento faltante na pergunta; nesses casos, o demandante evidencia ou, pelo menos, simula desconhecimento completo das possibilidades de resposta.

- Presença de antecipação: se ocorre (+) ou não (-) antecipação de resposta.

- Alternatividade: se a antecipação de resposta é alternativa (+) ou simples (-).

Quadro 3. Distinções entre opções em termos de "traços" e de restrição de resposta

\begin{tabular}{|c|c|c|c|c|}
\hline & $\begin{array}{c}\text { Restrição } \\
\text { de resposta } \\
\text { (validar, } \\
\text { selecionar e } \\
\text { preencher) }\end{array}$ & $\begin{array}{c}\text { Presença de } \\
\text { antecipação }\end{array}$ & Alternatividade & Exemplo \\
\hline $\begin{array}{c}\text { confirmativas sem } \\
\text { antecipação }\end{array}$ & validar & - & - & "Vamos para a praia?" \\
\hline $\begin{array}{c}\text { completivas com } \\
\text { antecip. simples }\end{array}$ & validar & + & - & $\begin{array}{c}\text { "Aonde vamos? Para a } \\
\text { praia?" }\end{array}$ \\
\hline $\begin{array}{c}\text { confirmativas com } \\
\text { antecipação }\end{array}$ & selecionar & + & + & $\begin{array}{c}\text { "Vamos para a praia ou } \\
\text { para casa?" }\end{array}$ \\
\hline $\begin{array}{c}\text { completivas com } \\
\text { antecip. alternat. }\end{array}$ & selecionar & + & + & $\begin{array}{c}\text { "Aonde vamos? Para a } \\
\text { praia ou para casa?" }\end{array}$ \\
\hline $\begin{array}{c}\text { completivas sem } \\
\text { antecipação }\end{array}$ & preencher & - & - & "Vamos aonde?" \\
\hline
\end{tabular}

Fonte: Elaboração própria

Como o foco, neste artigo, está na compreensão tipológica das demandas de informação em PB, não nos deteremos mais detalhadamente na proposta topológica. Trata-se, sobretudo, de uma sugestão de outra interpretação das categorias propostas, demonstrando que há continuidades: 1) entre declarações e perguntas confirmativas, por meio das declarações-pergunta; 2) entre perguntas confirmativas e completivas, por meio da ocorrência de restrições de resposta, fenômeno que se associa ao acesso ou não ao sistema de ANTECIPAÇÃO DE RESPOSTA. Note-se, entretanto, que se trata de dois continua diferentes: não propomos que perguntas completivas estejam mais "distantes" das declarações do que as confirmativas - é hipotetizável que exista um continuum entre declarações e completivas; porém, não investigamos essa possibilidade aqui.

De fato, para um trabalho exaustivo sobre perguntas em uma perspectiva topológica, seria necessário um estudo que, provavelmente, não veria a relação entre as opções como unidimensional (um "percurso" de declarações até completivas sem antecipação), mas sim como um espaço bidimensional - ou até tridimensional - de possibilidades. Deixamos tal trabalho, certamente muito profícuo, para estudos posteriores. 
- | A semântica das perguntas em português brasileiro: uma proposta sistêmico-funcional

\section{Considerações finais}

Neste artigo, foi proposta, com base nos estudos sistêmico-funcionais de Ruqaiya Hasan (1989, 2013, entre outros) sobre a semântica da mensagem, uma descrição da rede sistêmica das possibilidades de DEMANDA DE INFORMAÇÃo em português brasileiro e de suas realizações lexicogramaticais congruentes. Dessa forma, buscou-se descrever com maior delicadeza parte do sistema de FUNÇÕES DISCURSIVAS do PB.

Como mencionamos ao início do texto, embora esta descrição seja "pura", focando no potencial de significação do português brasileiro, o sistema aqui exposto é altamente aplicável. De fato, a motivação de Hasan (1983), ao propor sistemas semânticos para o inglês australiano na década de 1980, era fazer um estudo de forte preocupação social: compreender de que maneira as interações entre mães de diferentes posições sociais e seus filhos eram diferentes, e como tais diferenças afetavam o modo como crianças têm (ou não) acesso ao conhecimento e aos meios de produção de conhecimento (HASAN, 1989).

Há, porém, diversas outras aplicações para um sistema como o apresentado aqui. Williams (1994) utilizou a semântica da mensagem hasaniana para, ainda no domínio da educação, investigado por Hasan (1989), buscar uma compreensão aprofundada dos diferentes modos de leitura conjunta entre mães de posições sociais distintas e seus respectivos filhos. Lukin (2012), por sua vez, apontou a utilidade das redes sistêmicas propostas por Hasan para a análise crítica do discurso político. Finalmente, Moore (2016) demonstrou que a semântica da mensagem é altamente sensível à variação de registros e pode ser um bom parâmetro para a avaliação dos distintos modos como médicos lidam com pacientes que estão no fim da vida.

Cabe também enfatizar que, embora a descrição aqui apresentada tenha como base os estudos de Hasan, nosso sistema não é completamente incompatível com a interpretação de Martin (1992) sobre a semântica (discursiva) interpessoal, que resultou no sistema semântico-discursivo interpessoal de NEGOCIAÇÃO. De fato, seria muito apropriado buscar uma conciliação entre as semânticas interpessoais de Hasan e de Martin, porque Hasan chegou a categorias bastante delicadas, enquanto Martin possibilitou uma visão que dá conta de aspectos mais propriamente textuais, o que está em conformidade com a visão da LSF de língua como potencial que se instancia em textos. A categoria de "pergunta" (question) como demanda de informação também está no modelo de Martin, mas nele é enfatizado o fato de uma pergunta dar início a um par dialógico que tem como segunda parte a resposta. Pesquisas futuras sobre perguntas sob a perspectiva sistêmico-funcional sem dúvidas seriam beneficiadas por tal visão mais inclusiva, além de se aproximarem 
da tradição brasileira de pesquisas sobre o par pergunta-resposta (FÁVERO; ANDRADE, AQUINO, 2015).

Finalmente, deve-se apontar que a proposta aqui apresentada não se pretende exaustiva nem definitiva. As opções devem continuar sendo testadas tipológica e topologicamente, verificando sua distribuição em diferentes contextos e, sempre que possível, aprimorando as categorias propostas em termos de delicadeza (por exemplo, verificando os efeitos semânticos de diferentes partículas modais) - ou, se necessário, propondo reformas mais abrangentes do sistema. A descrição minuciosa das outras funções discursivas também seria de grande contribuição - idealmente, seria possível chegar a um "mapa" geral das funções discursivas e de suas inter-relações topológicas. Enfim, o estudo de realizações congruentes e incongruentes de cada uma das opções mais delicadas do sistema de perguntas é um terreno fértil e pouco explorado que, certamente, merece estudos aprofundados, especialmente pelo poder que a noção de metáfora gramatical tem na perspectiva sistêmico-funcional - e, no caso das metáforas gramaticais interpessoais, por suas possíveis contribuições à Pragmática dos Atos de Fala.

\section{Referências}

AUSTIN, J. L. How to do things with words. Oxford: Clarendon Press, 1962.

BATEMAN, J. A. The place of systemic functional linguistics as a linguistic theory in the twenty-first century. In: BARTLETT, T.; O'GRADY, G. The Routledge Handbook of Systemic Functional Linguistics. Oxon/New York: Routledge, 2017.

BATISTA JR., J. R. L.; SATO, D. T. B.; MELO, I. F. Análise de discurso crítica para linguistas e não linguistas. São Paulo: Parábola, 2018.

BRAGA, M. L.; BARBOSA, E. M. Construções clivadas no português do Brasil sob uma abordagem funcionalista. Matraga, v. 16, n. 24, p. 173-196, 2009.

FAIRCLOUGH, N. Analysing Discourse: Textual analysis for social research. London: Routledge, 2003.

FÁVERO, L. L.; ANDRADE, M.; AQUINO, Z. O par dialógico pergunta-resposta. In: JUBRAN, C. S. (org.). Gramática do Português Culto Falado no Brasil - v. I: a construção do texto falado. São Paulo: Contexto, 2015. p. 127-158. 
- | A semântica das perguntas em português brasileiro: uma proposta sistêmico-funcional

FIGUEREDO, G. P. Introdução ao perfil metafuncional do português brasileiro:

contribuições para os estudos multilíngues. 2011. Tese (Doutorado em Linguística Aplicada) - Faculdade de Letras, Universidade Federal de Minas Gerais, Belo Horizonte, 2011.

FIGUEREDO, G. P.; PAGANO, A. S.; FERREGUETTI, K. Os sistemas textuais de focalização na organização funcional da gramática do Português Brasileiro. DELTA: Documentação de Estudos em Linguística Teórica e Aplicada, v. 30, n. 2, p. 309-352, 2014.

FUNG, A. Hasan's Semantic Networks Revisited: a Cantonese Systemic Functional Approach. In: BOWCHER, W. L.; LIANG, J. Y (org.). Society in Language, Language in Society: Essays in Honour of Ruqaiya Hasan. New York: Palgrave, 2016. p. 115-140.

FUNG, A.; LOW, F. R. Semantic Networks. In: THOMPSON, G.; BOWCHER, W. L.; FONTAINE, L.; SCHOENTHAL, D. (org.). The Cambridge Handbook of Systemic Functional Linguistics. Cambridge: Cambridge University Press, 2019. p. 333-357.

FUZER, C.; CABRAL, S. R. S. Introdução à gramática sistêmico-funcional em língua portuguesa. Campinas: Mercado de Letras, 2014.

GONZAGA, J. J. Intricate Cases in Clauses in SFG concerning the Grammar of Brazilian Portuguese. 2011. Tese (Doutorado em Língua Inglesa e Linguística Aplicada) - Centro de Comunicação e Expressão, Universidade Federal de Santa Catarina, Florianópolis 2011.

GOUVEIA, C. A. M. Texto e gramática: uma introdução à Linguística Sistémico-Funcional. Matraga, v. 16, n. 24, p. 13-47, 2009.

HALLIDAY, M. A. K. Methods - techniques - problems. In: HALLIDAY, M. A. K.; WEBSTER, J. (org.). Continuum Companion to Systemic Functional Linguistics. London: Continuum International, 2009. p. 59-86.

HALLIDAY, M. A. K. Towards a theory of good translation. In: STEINER, E.; YALLOP, C. (org.). Exploring translation and multilingual text production: beyond content. Berlin/ New York: Mouton de Gruyter, 2001. p. 13-18.

HALLIDAY, M. A. K. An introduction to functional grammar. London: Edward Arnold, 1994.

HALLIDAY, M. A. K. Towards a language-based theory of learning. Linguistics and Education, v. 5, n. 2, p. 93-116, 1993. 
HALLIDAY, M. A. K. An Introduction to Functional Grammar. London: Edward Arnold, 1985.

HALLIDAY, M. A K. Language as code and language as behaviour: A systemic-functional interpretation of the nature and ontogenesis of dialogue. In: FAWCETT, R. P.; HALLIDAY, M. A. K.; LAMB, S. M.; MAKKAI, A. (org.) The Semiotics of Culture and Language, v. 1. London: Pinter, 1984. p. 3-36.

HALLIDAY, M. A. K. Explorations in the Functions of Language. London: Edward Arnold, 1973.

HALLIDAY, M. A. K.; GREAVES, W. S. Intonation in the Grammar of English. Sheffield: Equinox, 2008.

HALLIDAY, M. A. K.; HASAN, R. Cohesion in English. London: Longman, 1976.

HALLIDAY, M. A. K.; MATTHIESSEN, C. M. I. M. Introduction to Functional Grammar. 4. ed. New York/London: Routledge, 2014.

HASAN, R. A Semantic Network for the Analysis of Messages in Everyday Talk between Mothers and Their Children. Mimeo. 1983.

HASAN, R. Towards a paradigmatic description of context: systems, metafunctions, and semantics. Functional Linguistics, v. 1, n. 1, p. 1-54, 2014.

HASAN, R. Choice, System, Realisation: Describing Language as Meaning Potential. In: FONTAINE, L.; BARTLETT, T.; O'GRADY, G. (org.). Systemic Functional Linguistics: Exploring Choice. Cambridge: Cambridge University Press, 2013. p. 269-299.

HASAN, R. Semantic Variation: Meaning in Society and in Sociolinguistics. London: Equinox, 2009.

HASAN, R. Semantic networks: a tool for the analysis of meaning. In: CLORAN, C.; BUTT, D.; WILLIAMS, G. (org.). Ways of Saying: Ways of Meaning - Selected Papers of Ruqaiya Hasan. London: Cassell, 1996. p. 104-31.

HASAN, R. Semantic variation and sociolinguistics. Australian Journal of Linguistics, v. 9, n. 2, p. 221-275, 1989.

HASAN, R. Offers in the Making: a systemic functional approach. Mimeo. 1985. 
- | A semântica das perguntas em português brasileiro: uma proposta sistêmico-funcional

HASAN, R.; CLORAN, C.; WILLIAMS, G.; LUKIN, A. Semantic networks: The description of linguistic meaning in SFL. In: HASAN, R.; MATTHIESSEN, C.; WEBSTER, J. Continuing discourse on language: A functional perspective. London: Equinox, 2005.

HJELMSLEV, L. Prolegômenos a uma teoria da linguagem. São Paulo: Perspectiva, 2013.

JUBRAN, C. S. Tópico discursivo. In: JUBRAN, C. S. (org.). Gramática do Português Culto Falado no Brasil - v. I: a construção do texto falado. São Paulo: Contexto, 2015. p. 85-126.

LUKIN, A. Hasan's semantic networks as a tool in discourse analysis. In: KNOX, J. S. (org.). To boldly proceed: Papers from the 39th International Systemic Functional Congress. Sydney: 39th ISFC Organising Committee, 2012. p. 141-146.

MARTIN, J. R. English Text: System and Structure. Philadelphia: John Benjamins, 1992.

MARTIN, J. R.; MATTHIESSEN, C. M. I. M. Systemic typology and topology. In: CHRISTIE, F. (org.) Literacy in social processes: papers from the Inaugural Australian Systemic Functional Linguistics Conference. Darwin: Centre for Studies of Language in Education, 1991. p. 345-383.

MARTIN, J. R.; ROSE, D. Working with Discourse: Meaning beyond the clause. 2. ed. Continuum: Londres, 2007.

MARTIN, J. R.; WHITE, P. The language of evaluation: appraisal in English. Hampshire: Palgrave Macmillan, 2005.

MATTHIESSEN, C. M. I. M. Modelling context and register: the long-term project of registerial cartography. Letras, v. 25, n. 50, p. 15-90, 2015.

MATTHIESSEN, C. M. I. M. Systemic Functional Linguistics as appliable linguistics: social accountability and critical approaches. DELTA: Documentação de Estudos em Linguística Teórica e Aplicada, v. 28, n. esp., p. 435-471, 2012.

MATTHIESSEN, C. M. I. M. Lexicogrammatical Cartography: English Systems. Tokyo: International Language Sciences Publishers, 1995. 
MOORE, A. R. Can Semantic Networks Capture Intra- and Inter-Registerial Variation? Palliative Care Discourse Interrogates Hasan's Message Semantics. In: BOWCHER, W. L.; LIANG, J. Y (org.). Society in Language, Language in Society: Essays in Honour of Ruqaiya Hasan. New York: Palgrave Macmillan, 2016. p. 83-114.

PAGANO, A. S. Abordagens sistêmicas da tradução. In: CALDAS-COULTHARD, C. R.; SCLIAR-CABRAL, L. (org.). Desvendando discursos: conceitos básicos. Florianópolis: Editora da UFSC, 2008. p. 255-288.

RESENDE, V. M.; RAMALHO, V. Análise de Discurso Crítica. São Paulo: Contexto, 2006.

SÁ, M.; OLIVEIRA JR., M.; CUNHA, D.; LIMA, A. (org.). A linguagem falada culta na cidade do Recife - v. 3: diálogos entre dois informantes. Recife: Ed. UFPE, 2017.

SEARLE, J. R. Speech Acts: An Essay in the Philosophy of Language. London/New York: Cambridge University Press, 1969.

SEGUNDO, P. R. G. Linguística Sistêmico-Funcional e Análise Crítica do Discurso: explorando convergências e explicitando especificidades. Estudos Linguísticos, v. 43, n. 3, p. 1282-1297, 2014.

SILVA, W. R. Gêneros textuais em aulas de Língua Portuguesa no Ensino Médio brasileiro. Revista Linguagem \& Ensino, v. 15, n. 2, p. 387-418, 2012.

TAVERNIERS, M. The syntax-semantics interface in systemic functional grammar: Halliday's interpretation of the Hjelmslevian model of stratification. Journal of Pragmatics, v. 43, n. 4, p. 1100-1126, 2011.

WILLIAMS, G. Joint book-reading and literacy pedagogy: A socio-semantic examination. 1994. Tese (Doutorado em Linguística) - Sydney: Macquarie University, 1994.

COMO CITAR ESTE ARTIGO: FARHAT, Theodoro Casalotti; GONÇALVESSEGUNDO, Paulo Roberto. A semântica das perguntas em português brasileiro: uma proposta sistêmico-funcional. Revista do GEL, v. 18, n. 2, p. 35-65, 2021. Disponível em: https://revistadogel.gel.org.br/

Submetido em: 28/03/2021 | Aceito em: 21/05/2021. 